\title{
Secondary Iliac-Enteric Fistula to the Sigmoid Colon Complicated with Entero- Grafto-Cutaneous Fistula
}

\author{
Gábor Bognár ${ }^{\mathrm{a}}$ István Sugár ${ }^{\mathrm{a}} \quad$ Péter Sipos ${ }^{\mathrm{a}}$ \\ György Ledniczky á Ágnes Laczkób Pál Ondrejka ${ }^{a}$ \\ ${ }^{a} 2$ nd Department of Surgery and bepartment of Vascular and Cardiac Surgery, \\ Semmelweis University, Budapest, Hungary
}

\section{Key Words}

Aortoilac surgery $\cdot$ Graft $\cdot$ Sigmoid colon $\cdot$ Fistula $\cdot$ Rectal bleeding $\cdot$ Vascular prosthesis

\begin{abstract}
We report the case of a 67-year-old man who was admitted to our department with acute rectal bleeding. The patient had had previous aortoiliac surgery with the utilization of an aortobifemoral vascular prosthesis. Diagnosis of aortoenteric fistula was made between the distal suture line of the right graft leg and the sigmoid colon. This fistula had an enterocutaneous component. After exploratory laparotomy, primary resection of the sigmoid colon, exstirpation of the enterocutaneous fistula, excision of the right graft leg and extraanatomical crossover bypass were successfully performed. This study reports a rare type of aorto/ilac-enteric fistula to the left colon complicated with an entero-graftocutaneous component and describes an unusual and successful surgical treatment method.
\end{abstract}

\section{Introduction}

Aortoenteric fistula (AEF) is a communication between the aorta and any segment of the gastrointestinal tract. Although Sir Astley Cooper [1] was the first to describe arterioenteric fistula, as a complication of abdominal aneurysm, Salmon [2] presented the first case report in 1843. Primary AEF occurs in patients with intestinal malignancies or inflammatory bowel diseases or primary vascular diseases such as aneurysms. Secondary AEF is a complication after aortic surgery using vascular prosthesis [3]. AEF occurs in $0.3-2 \%$, but is associated with a hospital mortality between $25-90 \%[4,5]$. It is also associated with important morbidity with a lower limb amputation rate of $9 \%$, and a $15 \%$ risk for renewed graft infection [4]. On the gastrointestinal side of the fistula, duodenum 
is mostly involved (87\%), followed by small bowel, especially the ileum (4\%), and very rarely stomach and esophagus $[3,6]$. The incidence of AEF to the large bowel is under $2 \%$ [7]. Regarding the vascular side of the fistula, in nearly all cases the aorta or the proximal suture line (on aorta) is involved. There are only few case reports on communication between iliac graft leg and the large bowel $[7,8]$. This rare type of fistula is generally called AEF.

The aim of this study is to report a rare type of secondary AEF to the sigmoid colon complicated with fistula between the AEF and the skin, which was effectively diagnosed and successfully treated.

\section{Case Report}

A 67-year-old man was admitted to our department with intermittent rectal bleeding for the last 5 days. The bleeding became more intense in the last $12 \mathrm{~h}$ and was associated with bleeding from a cutaneous fistula in the right inguinal region. This fistula had appeared 4 weeks earlier and produced only a small amount of fecopurulent exudate. Abdominal computed tomography (CT) scans showed inflammatory bunch in the right inguinal region, with air bubbles inside a fistulous formation in the middle (fig. 1). There was no history of fever or weight loss. The patient was hemodynamically stable and physical examination showed only mild paleness. Four years earlier, the patient had had a history of an aortoiliac aneurysm managed by an elective surgical intervention, with interposition of an aortobifemoral Dacron graft with no immediate postoperative complications.

At the emergency admission the hematological findings confirmed severe anemia $(\mathrm{Hb}=6.6 \mathrm{~g} / \mathrm{dl}, \mathrm{Ht}$ $=18 \%$ ). Urgent esophagogastroduodenoscopy was performed with normal findings. Abdominal ultrasonography showed a vascular mass in the hypogastric region, whereas abdominal CT scans showed an inflammatory mass surrounding the graft in direct contact with the right inguinal region of the sigmoid colon (fig. 2). Colonoscopy revealed blood in the rectum, sigmoid wall lesion secondary to an extrinsic pulsate graft protruding into the lumen of the bowel (fig. 3 ). Fistulography showed direct communication to the sigmoid colon (fig. 4 ).

The patient underwent immediate laparotomy. Intraoperative findings included a pulsatile mass in direct contact with the sigmoid colon, which showed signs of hematic infiltration of its wall. Mobilization of the sigmoid colon confirmed the erosion of the right graft leg into the bowel, surrounded by the inflammatory mass and psedoaneurysm, also communicating with the cutaneous fistula. Excision of right graft, oversewing of its stump, and resection of the sigmoid colon with primary suture were performed. The enterocutaneous fistula was extirpated completely. An extraanatomic bypass was created using femoro-femoral crossover Dacron graft to reestablish blood flow to the right lower extremity.

Pathological examination of the colon showed not ischemic necrosis of the sigmoid colon, but inflammatory findings of the bowel wall, locally, on the erosion of the prosthesis.

The patient was discharged from the hospital on the twenty-fourth postoperative day. He had no neuromuscular deficits or infectious complications.

\section{Discussion}

AEF is rare complication after aortic surgery. The incidence of the disease varies from 0.3 to $2 \%$ [5], with high mortality $(25-90 \%)[4,5]$. The mean interval between the first procedure and the appearance of AEF is 3 years (range 1-15) [6]. AEF related to the distal suture line of the prosthesis is rare in the literature $[3,9,10]$.

Two main mechanisms have been related with development of this disease: infection and mechanical disturbances $[3,6,11]$. Some microorganisms are frequently associated with infection of the graft, such as Staphylococcus aureus, Bacteroides fragilis, Streptococcus faecalis, and many Escherichia coli subtypes. However, there is no 
correlation between specific bacterial infection and suture line, pseudoaneurysm formation, or severity of the infectious process. Fistulization occurs in $12-33 \%$ of cases who have infected graft [12]. In the case reported above, fistulization between colon and aorta/iliac artery occurred in the proximal part of the right graft, an infrequent observation.

Mechanical factors can also be implicated in the pathogenesis of AEF. Bowel adherences with mechanical erosions can lead to fistulization. There are suggestions for covering the anastomosis with peritoneum or greater omentum [13]. In our case the graft had eroded the complete bowel wall and appeared in the lumen of the sigmoid colon.

The prosthesis material does not seem to influence the incidence of fistula, but recent suture materials are more rarely related to suture line disruption and pseudoaneurysm formation than the silk line ones [14].

The symptoms of the disease depend of the stage of fistula formation. Infectious or hemorrhagic signs can be present in AEF. Fever and malaise are part of the septic component of the disease, combined with abdominal pain. Gastrointestinal bleeding as another clinical sign will occur according to the segment of the bowel involved [14]. This can lead to anemia in occult cases and to hemorrhagic shock in acute cases.

A successful outcome allows early diagnosis and prompt surgical intervention. Any clinical manifestation listed above and previous aortic surgery in the anamnesis can suggest the manifestation of AEF.

The first eligible diagnostic tool is endoscopy, which can prove the site of bleeding in $80 \%$ of those examined [15]. In the presence of melena, esophagogastroduodenoscopy is recommended; when rectal bleeding is present, colonoscopy is necessary [11]. CT scans can help diagnose the infectious signs of the disease [16], as effacement of the periaortic or perigraft fat plane and the fat plane between the aorta and bowel (100\%), perigraft soft tissue (100\%), bowel wall thickening adjacent to the graft (89\%), perigraft fluid (78\%), perigraft hematoma (67\%), pseudoaneurysm or aneurysm bulge (67\%), ectopic gas (56\%), and dystrophic vascular graft calcification (11\%) [16].

A recent study showed a sensitivity rate of $83.3 \%$ for this imaging technique, with specificity and accuracy rates of 99.7 and $93.7 \%$, respectively [17]. Also 18fluorodeoxyglucose positron emission tomography can diagnose the fistula in selected cases [8]. Aortography is rarely helpful in diagnosing AEF, since even the fistula can be occluded by a thrombus or can be too long and/or not large enough [7]. In such a case technetium-99m-labelled red blood cell scintigraphy can help [18]. A new diagnostic tool is intravascular ultrasound. After a prompt diagnosis, it can open the way to endovascular treatment [5].

In the case reported here, colonoscopy was very useful for the diagnosis, revealing blood in the rectum and showing erosion of the graft through the sigmoid wall. Fistulography confirmed the location of the AEF and allowed prompt surgical intervention.

Surgical intervention is unavoidable even though it can be arduous and may need assistance of vascular and gastrointestinal surgeons. The removal of the infected graft is recommended because the presence of bacterial inoculation can lead to persistent infection and sepsis [6]. Reestablishment of blood flow to the lower extremities can be performed by an extraanatomical bypass, usually axillofemoral or femorofemoral 


\begin{tabular}{c|l|l|l}
$\begin{array}{c}\text { Case Reports in } \\
\text { Gastroenterology }\end{array}$ & $\begin{array}{l}\text { Case Rep Gastroenterol 2008;2:138-143 } \\
\text { D0I: 10.1159/000121470 }\end{array}$ & Published online: April 17, 2008 & $\begin{array}{l}\text { O 2008 S. Karger AG, Basel } \\
\text { ISSN 1662-0631 } \\
\text { www.karger.com/crg }\end{array}$ \\
\hline
\end{tabular}

bypasses [7]. No significant difference in postoperative mortality and complications was observed when using fresh or cryopreserved homografts for reconstruction [6].

The repair strategy of the large bowel defect is still debated. Hartmann's procedure is frequently recommended in cases with severe septic condition, when the danger of suture insufficiency is high. Primary resection and reconstruction or subtotal colectomy can be accomplished in selected cases. Generally, the type of the surgical intervention depends on the situation, location, extension and hemodynamic condition of the patient.

One new approach is endovascular treatment, which might be a valid alternative to open surgery and can be proposed in patients who are at high surgical risk. Further studies with larger series are necessary to confirm the long-term effectiveness of this procedure [19].

\section{Conclusion}

AEF is rare complication of aortic surgery. Fistulization between the distal suture line of the aortoiliac graft leg and the sigmoid colon is extreme unusual. In our case, this formation of AEF was complicated by a bleeding entero-grafto-cutaneous fistula, a manifestation which has not been described yet.

Fig. 1. Left inguinal fistula (arrow) surrounded by inflammatory mass.

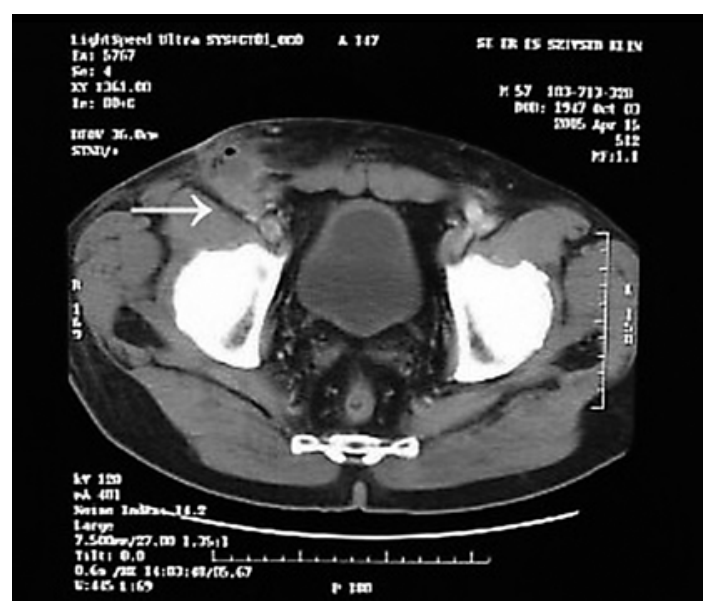


Fig. 2. Enterocutaneous fistula (arrow). CT shows inflammatory mass surrounding the graft in direct contact with the right inguinal region and the sigmoid colon.

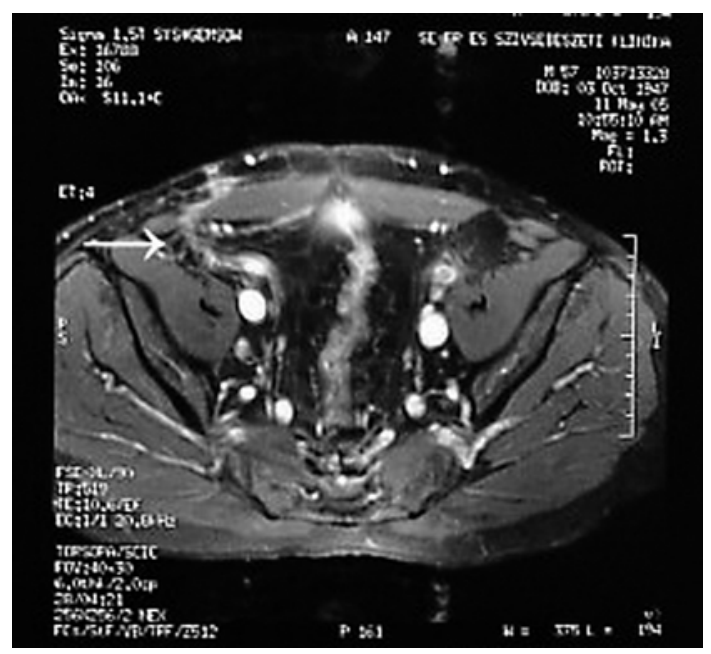

Fig. 3. Colonoscopy: The graft eroded the sigmoid wall.

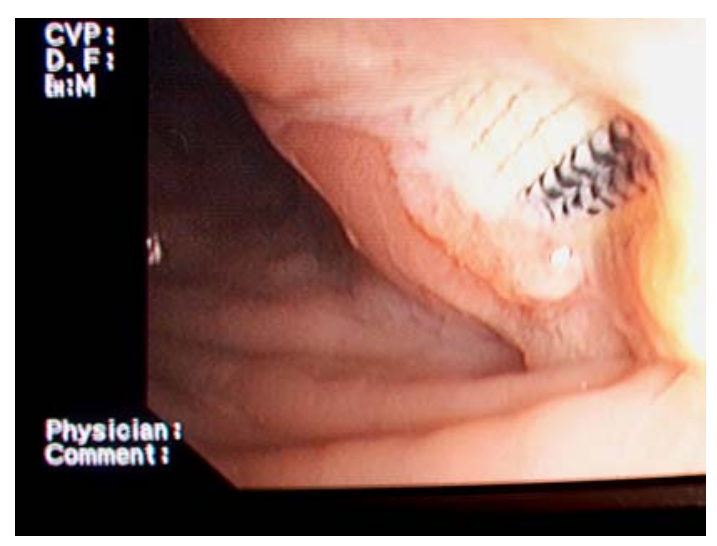

Fig. 4. Fistulography: Sigmoidocutaneous fistula (cannula in the right inguinal region).

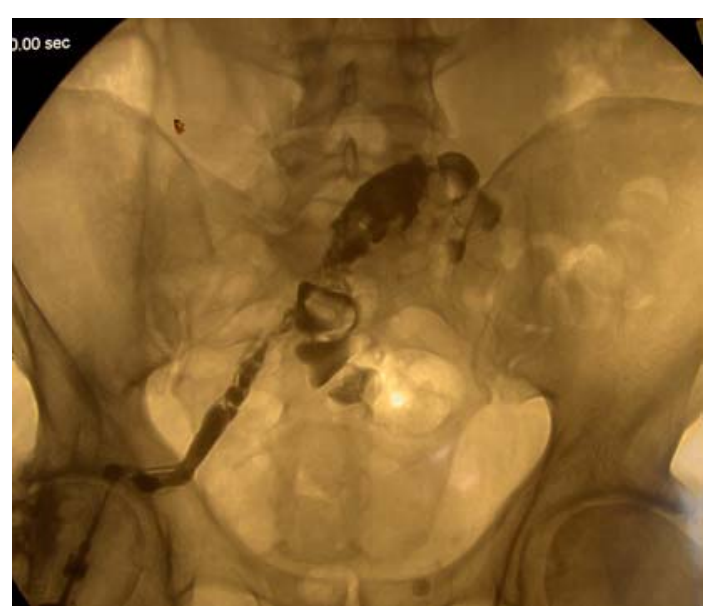




\section{References}

1 Cooper A: Lectures on the Principles and Practice of Surgery with Additional Notes and Cases by F. Tyrell, 5th ed. Philadelphia, Haswell, Barringron \& Haswell, 1839.

2 Salmon M: Aneuryme de l'aorte ventrale: Mort par rupture de la poche artérielle dans le duodénum. Bull Soc Anat 1843;283:18-28.

3 Bunt TJ: Synthetic vascular graft infections II. Graft-enteric erosions and graftenteric fistulas. Surgery 1983;94:1-9.

4 Sierra J, Kalangos A, Faidutti B, Christenson JT: Aorto-enteric fistula is a serious complication to aortic surgery. Modern trends in diagnosis and therapy. Cardiovasc Surg 2003;11:185-188.

5 Maternini M, Tozzi P, Vuilleumier H, Von Segesser LK: Intra vascular ultra sound: one more tool to diagnose aorto-duodenal fistula. Eur J Vasc Endovasc Surg 2006;32:542-544.

-6 Chiesa R, Astore D, Frigerio S, Garriboli L, Piccolo G, Castellano R, Scalamogna M, Odero A, Pirrelli S, Biasi G, Mingazzini P, Biglioli P, Polvani G, Guarino A, Agrifoglio G, Tori A, Spina G: Vascular prosthetic graft infection: Epidemiology, bacteriology, pathogenesis and treatment. Acta Chir Belg 2002;102:238-247.

7 Perez RO, Katayama FF, Brasciani C, Jacob CE, Coser RB, Alves PRA, HabrGama A, Gama-Rodrigues JJ, Kiss DR, Cimelli M: Aortoenteric fistula to the sigmoid colon - case report. Curr Surg 2005;62:49-54.

8 Tsunekawa T, Ogino H, Minatoya K, Matsuda H, Sasaki H, Fukochi K: Masked prosthetic graft to sigmoid colon fistula diagnosed by 18-fluorodeoxyglucose positron emission tomography. Eur J Vasc Endovasc Surg 2007,33:187-189.

-9 Moulton S, Adams M, Johansen K: Aortoenteric fistula. A 7 year urban experience. Am J Surg 1986;151:607-611.

10 Grande JP, Ackermann OM, Edwards WO: Aortoenteric fistulas. A study of 28 autopsied cases spanning 25 years. Arch Pathol Lab Med 1989;113:1271-1275.

11 Antinori CH, Andrew CT, Santaspirt JS, et al: The many faces of aortoenteric fistula. Am Surg 1996;62:344-349.

12 Gutowski P: Aortoiliac graft infection as a diagnostic and treatment problem. Ann Acad Med Stetin 1998;suppl 41:1-72.

13 England DW, Simms MH: Recurrent aorto-duodenal fistula: A final solution? Eur J Vasc Surg 1990;4:427-429.

14 Busuttil RW, Rees W, Baker JO, Wilson SE: Pathogenesis of aortoduodenal fistula: experimental and clinical correlates. Surgery 1979;85:1-13.

15 Champion MC, Sullivan SN, Coles JC, Goldbach M, Watson WC: Aortoenteric fistula. Incidence, presentation recognition, and management. Ann Surg 1982;195:314-317.

16 Hagspiel KD, Turba UC, Bozlar U, Harthun NL, Cherry KJ, Ahmet H, Bickstone SJ, Angle JF: Diagnosis of aorto-enteric fistulas with CT angiography. J Vasc Interv Radiol 2007;18:497-504.

17 lino M, Kuribayashi S, Imakita S, Takamiya M, Matsuo H: Sensitivity and specificity of CT in the diagnosis of inflammatory abdominal aortic aneurysms. J Comput Assist Tomogr 2002;26:1006-1012.

18 Gerard PS, Gerczuk PZ, Idupuganti R, Patnama M: Massive gastrointestinal bleeding due to an aorto-enteric fistula seen by technetium-99m-labelled red blood cell scintigraphy. Clin Nucl Med 2007;32:551-552.

19 Lagana D, Carrafielo G, Mangini M, Recaldini C, Lumia D, Cuffari S, Caronno R, Castelli P, Fugazzola C: Endovascular treatment of anastomic pseudoaneurysms after aorto-ilac surgical reconstruction. Cardiovasc Intervent Radiol 2007;30:1185-1191. 